This paper is published as: Lignos, D.G., Hartloper, A.R., Elkady, A., Deierlein, G.G., Hamburger, R. (2019). "Proposed updates to the ASCE 41 nonlinear modeling parameters for wide-flange steel columns in support of performance-based seismic engineering, Vol. 145(9), pp. 04019083, doi: 10.1061/(ASCE)ST.1943541X.0002353

\title{
Proposed Updates to the ASCE 41 Nonlinear Modeling Parameters for Wide-Flange Steel Columns in Support of Performance-based Seismic Engineering
}

\author{
Dimitrios G. Lignos, M.ASCE${ }^{1}$, Alexander R. Hartloper²; Ahmed Elkady, A.M.ASCE; \\ Gregory G. Deierlein, F.ASCE ${ }^{4}$, and Ronald Hamburger, F. ASCE 5
}

\section{Abstract}

Nonlinear static and dynamic analyses are utilized by engineers for performance-based seismic risk evaluation of new and existing structures. In this context, nonlinear component modeling criteria are typically based on ASCE 41 guidelines. Experiments on wide-flange steel columns suggest that the ASCE 41-13 nonlinear component models do not adequately reflect the expected steel column behavior under cyclic loading. To help bridge the gap between state-ofthe-art research and engineering practice, this paper proposes new modeling criteria for the first-cycle envelope and monotonic backbone curves of steel columns for use in nonlinear static and dynamic frame analysis. The proposed nonlinear provisions include new parameters for concentrated hinge models to facilitate modeling of strength and stiffness deterioration of steel columns under seismic loading. The associated variability in the model parameters is also quantified to facilitate reliability analyses and development of probabilistic acceptance criteria for design. Recommendations are made to account for the influence of bidirectional lateral loading and varying axial load demands on the steel column's hysteretic behavior. Also proposed is an increase in the compression axial force limit for characterizing columns as forceversus deformation-controlled in line with the new ASCE 41 provisions. The proposed modeling parameters are validated against test data and continuum finite element analyses, and they are proposed for consideration in future updates to ASCE 41 requirements for nonlinear static and dynamic analyses of steel frame buildings with wide-flange columns.

\footnotetext{
${ }^{1}$ Associate Professor, École Polytechnique Fédérale de Lausanne (EPFL), Switzerland

2 Doctoral Assistant, École Polytechnique Fédérale de Lausanne (EPFL), Switzerland

${ }^{3}$ Post-Doctoral Research Scientist, École Polytechnique Fédérale de Lausanne (EPFL), Switzerland

${ }^{4}$ John A. Blume Professor, Stanford University, Stanford, CA, USA

${ }^{5}$ Senior Principal, Simpson Gumpertz \& Heger (SGH), San Francisco, CA, USA
} 
This paper is published as: Lignos, D.G., Hartloper, A.R., Elkady, A., Deierlein, G.G., Hamburger, R. (2019). "Proposed updates to the ASCE 41 nonlinear modeling parameters for wide-flange steel columns in support of performance-based seismic engineering, Vol. 145(9), pp. 04019083, doi: 10.1061/(ASCE)ST.1943541X.0002353

Author keywords: Steel wide-flange columns; ASCE 41; Nonlinear component modeling; Performance-based seismic engineering; Steel frame buildings; cyclic deterioration; model uncertainty.

\section{Introduction}

Performance assessment by nonlinear dynamic (response history) analyses is being increasingly used for the seismic assessment and design of buildings and other structures. Over the past decade or so, general guidelines and criteria have been proposed for the use of nonlinear dynamic analyses of tall buildings (e.g., LATBSDC 2017; PEER 2017) and other structures (Deierlein et al. 2010). Most recently, the ASCE 7 standard has introduced a new chapter on nonlinear dynamic analysis for seismic design (ASCE 2017a; Haselton et al. 2017). While general guidelines for implementation of nonlinear dynamic analyses have advanced, detailed recommendations and criteria for structural components have not advanced as quickly. For example, many engineers rely on model parameters in the ASCE 41 standard (ASCE 2014, 2017b), which date back to guidelines developed for nonlinear static (pushover) analyses in the late 1990s (ATC 1997; FEMA 1997a; b).

In the last decade, guidelines geared to nonlinear dynamic analysis of steel and concrete buildings have been developed, including updated component hysteretic models that explicitly capture cyclic strength and stiffness deterioration (PEER/ATC 2010). These models reflected the most recent findings from laboratory testing of steel beams in pre-qualified beam-tocolumn connections (FEMA 2000; Lignos and Krawinkler 2011) that were mainly tested as part of the SAC joint venture program. Due to the fairly limited experimental data available at the time, it was recognized that updated modeling recommendations should be provided to properly model the hysteretic response of steel columns subjected to seismic loading (PEER/ATC 2010; Hamburger et al. 2016).

More recently, several full-scale experiments have been conducted to characterize the hysteretic behavior of steel columns under multi-axis cyclic loading (Newell and Uang 2008; Suzuki and Lignos 2015, 2017; Lignos et al. 2016; Ozkula et al. 2017; Elkady and Lignos 2018a). Although these tests revealed that the plastic deformation capacity of steel columns is strongly influenced by the cross-section and member slenderness as well as the applied axial load on the column, the ASCE 41-13 skeleton curve deformation parameters do not properly 
This paper is published as: Lignos, D.G., Hartloper, A.R., Elkady, A., Deierlein, G.G., Hamburger, R. (2019). "Proposed updates to the ASCE 41 nonlinear modeling parameters for wide-flange steel columns in support of performance-based seismic engineering, Vol. 145(9), pp. 04019083, doi: 10.1061/(ASCE)ST.1943541X.0002353

capture these dependencies. This has been also recognized by practicing engineers (Bech et al. 2015).

The ASCE 41-13 standard treats steel columns as force-controlled elements (i.e., zero plastic deformation capacity) when they are subjected to compressive axial load demands of more than $50 \% P_{C L}$ (where $P_{C L}$ is the lower-bound axial compressive strength of a steel column as defined in AISC-341-16 (AISC 2016a)). This limit may lead into seismic retrofit solutions that often times are needlessly costly (Bech et al. 2015). On the other hand, experimental evidence and corroborating continuum finite element simulations (Newell and Uang 2008; Elkady and Lignos 2015, 2018a, 2018b; Lignos et al. 2016) suggest that seismically compact steel columns as per AISC-341-16 (AISC 2016a) can develop appreciable plastic deformation capacities even at relatively high compressive axial load demands. Although the recently published ASCE 41-17 provisions (ASCE 2017b) raised the associated limit for forcecontrolled column elements to $50 \% P_{y e}\left(P_{y e}\right.$ is the axial yield strength and is calculated based on expected steel material properties) or less, depending on the section compactness, there is no background information to substantiate such change.

Steel-framed structures are often subjected to bidirectional loading due to three dimensional (3D) ground motion shaking. Similarly, end (i.e., corner) columns of steel moment resisting frames (MRFs) may experience large fluctuations of axial load demands due to dynamic overturning effects; hence, their hysteretic behavior is different than that of adjacent interior steel MRF columns within the same MRF story (Suzuki and Lignos 2015). In particular, interior steel MRF columns do not experience axial load fluctuations due to overturning forces. The ASCE 41-17 (ASCE 2017b) provisions do not provide explicit guidance on how to address the aforementioned two effects.

Despite the fact that both FEMA 273/274 (FEMA 1997a; b) and ASCE 41-17 (ASCE 2017b) did not intend for the use of first and/or second cycle component curves in nonlinear dynamic analysis, absent of other established hysteretic models, engineers often apply the ASCE 41 component models for dynamic analyses (Hamburger et al. 2016). Although this issue was explicitly addressed for steel beams (PEER/ATC 2010; Lignos and Krawinkler 2011) with the use of hysteretic models that incorporate cyclic deterioration in strength and stiffness (e.g., Ibarra et al. 2005), it still remains a challenge for steel columns. This requires sufficient monotonic data as well as data from different cyclic loading histories that represent the seismic demands induced in steel frame buildings by different earthquakes and seismic intensities 
This paper is published as: Lignos, D.G., Hartloper, A.R., Elkady, A., Deierlein, G.G., Hamburger, R. (2019). "Proposed updates to the ASCE 41 nonlinear modeling parameters for wide-flange steel columns in support of performance-based seismic engineering, Vol. 145(9), pp. 04019083, doi: 10.1061/(ASCE)ST.1943541X.0002353

(Krawinkler 2009; Maison and Speicher 2016). It also requires a sense of the associated uncertainty for the first-cycle and monotonic backbone input model parameters such that load and resistance factors can be applied to the associated seismic demands (computed from analysis). Furthermore, acceptance criteria for both deformation- and force-controlled elements can be defined in a similar manner with Chapter 16 of ASCE 7-17 (ASCE 2017b).

This paper addresses the aforementioned deficiencies by utilizing the available experimental data, complemented with high-fidelity continuum finite element (CFE) simulations on steel wide-flange columns. In conjunction, detailed background information and refined nonlinear modeling recommendations are proposed for the ASCE 41 standard. These include updating the parameters of the ASCE 41 component model, as well as characterizing the monotonic response of steel columns (i.e., monotonic backbone curves). The above are achieved in the form of empirical regression models that can be effectively used in engineering practice. Recommendations are also made for modeling the cyclic deterioration in strength and stiffness by utilizing a commonly used phenomenological deterioration model. This paper comprises part of the work carried out under the ATC-114 project funded by the National Institute of Standards and Technology (NIST) to propose updated recommendations for all four major structural materials (Hamburger et al. 2017) as well as guidelines for nonlinear structural analysis and design of buildings with steel moment frames (Deierlein et al. 2017, 2018).

\section{Component Model Description}

Figure 1a shows the moment-rotation relation of two nominally identical columns (termed as "Test data") tested under monotonic and symmetric cyclic lateral loading histories (Suzuki and Lignos 2015). The first cycle-envelope curve is derived as a series of secants connecting the peaks of each first-cycle loading excursion of a symmetric loading history in the positive and negative loading direction. The idealized multi-linear monotonic backbone and first-cycle envelope curves are superimposed in the same figure (plotted in dashed lines). Although the first-cycle envelope curve is loading-history dependent (FEMA 2009; Krawinkler 2009), it is typically used in nonlinear static analysis so as the effects of cyclic deterioration in strength and stiffness are implicitly reflected in the member's response. On the other hand, a member's monotonic backbone curve is considered as a unique property. It can be used for nonlinear dynamic analysis procedures provided that the employed component hysteretic model 
This paper is published as: Lignos, D.G., Hartloper, A.R., Elkady, A., Deierlein, G.G., Hamburger, R. (2019). "Proposed updates to the ASCE 41 nonlinear modeling parameters for wide-flange steel columns in support of performance-based seismic engineering, Vol. 145(9), pp. 04019083, doi: 10.1061/(ASCE)ST.1943$541 \mathrm{X} .0002353$

118 explicitly simulates the effects of cyclic deterioration in strength and stiffness (e.g., Ibarra et al. 2005; Krishnan 2010; Sivaselvan 2013).

120 Referring to Fig. 1b, the modeling parameters of the first-cycle envelope curve are distinguished from those of the monotonic backbone with a superscript asterisk (*). The effective elastic stiffness, $K_{e}$ of a steel column considers both its flexural and shear deformations. The yield point is defined by the effective yield strength, $M_{y}^{*}$, and the corresponding yield rotation, $\theta_{y}^{*}$. In the post-yield range, the column hardens prior to reaching its maximum flexural strength, $M_{\max }^{(*)}$ (i.e., peak response). This point is associated with the onset of geometric instabilities (i.e., local and/or lateral torsional buckling). the effective yield strength, $M_{y}^{*}$ is calculated based on a straight line from the peak response $\left(M_{\max }^{(*)}\right)$ that intersects the elastic slope of the column (i.e., effective stiffness, $K_{e}$ ). The slope of this line is such that the positive and negative areas between the first-cycle envelope (or monotonic curve) and the line itself are equal in an absolute manner (i.e., equal area rule (Chopra and Goel_2001)). The pre-peak plastic rotation, $\theta_{p}^{(*)}$ defines the column's plastic deformation up to the peak response. Following the onset of geometric instabilities, the column's response is represented by the postpeak plastic rotation, $\theta_{p c}^{(*)}$. Stabilization of the local buckling amplitude occurs at a residual moment, $M_{r}^{(*)}$ (Krawinkler et al. 1983). Finally, a steel column losses its axial load carrying capacity at an ultimate rotation, $\theta_{u l t}^{(*)}$, which is dominated by severe axial shortening (Suzuki and Lignos 2015).

The modified Ibarra-Medina-Krawinkler (IMK) phenomenological component model (Ibarra et al. 2005; Lignos and Krawinkler 2011) explicitly captures a component's cyclic deterioration in strength and stiffness. The model assumes that each component has an inherit reference hysteretic energy property, represented by a parameter $\Lambda$. This is known as the reference cumulative plastic rotation capacity (Lignos and Krawinkler 2011). This property, which is assumed to be loading-history independent, controls the rate of deterioration in basic strength, $\Lambda_{s}$, post-peak strength, $\Lambda_{c}$, and unloading stiffness, $\Lambda_{k}$ of a structural steel component.

Referring to Figs. 1c and 1d, the simulated hysteretic response based on the modified IMK model is compared with two nominally identical column tests subjected to different loading histories (Elkady and Lignos 2018a). In brief, the first one is a standard symmetric loading history (Krawinkler et al. 2000). The second one is asymmetric (termed as collapse protocol) and imposes a structural component on few inelastic cycles followed by large monotonic 
This paper is published as: Lignos, D.G., Hartloper, A.R., Elkady, A., Deierlein, G.G., Hamburger, R. (2019). "Proposed updates to the ASCE 41 nonlinear modeling parameters for wide-flange steel columns in support of performance-based seismic engineering, Vol. 145(9), pp. 04019083, doi: 10.1061/(ASCE)ST.1943$541 X .0002353$

149 pushes (so-called ratcheting) prior to structural collapse. This protocol has been established

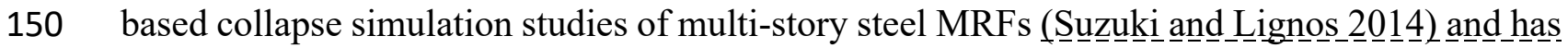

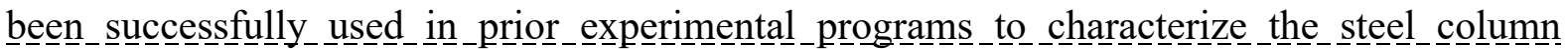

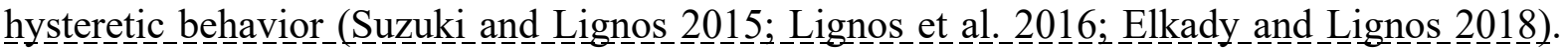

The figures suggest that, by utilizing the monotonic backbone curve with properly calibrated deterioration parameters, the IMK model can simulate the cyclic strength and stiffness deterioration reasonably well, regardless of the imposed loading history. Therefore, this model is adopted herein to provide explicit modeling guidelines for steel columns in support of nonlinear dynamic analysis procedures in a similar manner with steel beams (Lignos and Krawinkler 2011). The utilized data is also publicly available (http://resslabtools.epfl.ch/) for the development of similar guidelines through the use of other available deterioration models.

\section{Steel Column Database for Component Model Calibration}

161 The component models discussed in the previous section are calibrated with available experimental data on 151 steel columns (MacRae et al. 1990; Nakashima et al. 1990; Newell and Uang 2008; Cheng et al. 2013; Chen et al. 2014; Suzuki and Lignos 2015, 2017; Lignos et al. 2016; Elkady and Lignos 2017, 2018a; Ozkula et al. 2017). The collected tests involve columns subjected to unidirectional and bidirectional bending under monotonic and reversed cyclic symmetric lateral loading histories coupled with constant compressive axial load demands. Datasets including varying axial load demands were also considered (Suzuki and Lignos 2015, Lignos et al. 2016). Figure 2a shows the ranges of the local flange and web slenderness ratios, $b_{f} / 2 t_{f}$ and $h / t_{w}$, respectively, of the collected data. It is common that some data points overlap one another because multiple tests were conducted on nominally identical members. The majority of the cross-sections satisfy the compactness limits of highly ductile members, $\lambda_{h d}$, per AISC 341-16 (AISC 2016a). Because the dataset is limited to hot-rolled cross-sections, there is a relatively strong linear correlation (i.e., correlation coefficient of 0.79 ) between $b_{f} / 2 t_{f}$ and $h / t_{w}$.

Figure $2 \mathrm{~b}$ shows the gravity-induced compressive axial load ratio, $P_{g} / P_{y e}$ (where $P_{g}$ is the gravity-induced compressive load) applied on those column tests versus $h / t_{w}$. Notably, several columns were tested with a $P_{g} / P_{y e}>50 \%$ (i.e., $P / P_{C L}>50 \%$ ), allowing for a re-assessment of the ASCE 41-13 (ASCE 2014) compressive axial load limit to the current ASCE 41-17 (ASCE 2017b) limit for force-controlled elements as discussed later on. Referring to Fig. 2, the 
This paper is published as: Lignos, D.G., Hartloper, A.R., Elkady, A., Deierlein, G.G., Hamburger, R. (2019). "Proposed updates to the ASCE 41 nonlinear modeling parameters for wide-flange steel columns in support of performance-based seismic engineering, Vol. 145(9), pp. 04019083, doi: 10.1061/(ASCE)ST.1943$541 \mathrm{X} .0002353$

180 database is sparsely populated for the purpose of component model calibration. Therefore,

181

182

183

184

185

186

187

188

189

190

191

192

193

194

195

196

197

198

199

200

201

202

203

204

205

206

207

208

209

210

additional data points were generated using high-fidelity CFE simulations to fill the gaps in both the cross-section slenderness and axial load ranges. This includes nearly $1000 \mathrm{CFE}$ simulation data points. In brief, the CFE model specifics comprise a number of key characteristics. In particular, shell elements that are assigned member and local imperfections within the allowable limits of AISC-360-16 (AISC 2016b) and ASTM (2015), respectively, to properly trace geometric instabilities associated with local and lateral torsional buckling. Residual stresses due to hot-rolling are appropriately considered based on the Young (1971) stress distribution. The steel material inelasticity is simulated through a multiaxial plasticity model (Voce 1948; Armstrong and Frederick 1966; Chaboche 1989) that captures the combined effects of the isotropic/kinematic hardening of mild steels. The parameters of this model are calibrated as discussed in Elkady and Lignos (2018b) and Suzuki and Lignos (2017). Nonlinear static analysis is used including geometric nonlinearities based on the Newton solution method. A direct linear equation solver is employed that features a sparse, direct, Gauss elimination method. The column base degrees of freedom are restrained to mimic ideally fixed boundary conditions in steel MRFs. On the other hand, the column top end boundary is flexible mimicking the boundary conditions of first-story steel columns in capacity-designed steel MRFs. All the CFE simulations were carried out with ABAQUS (A_BA_AQUS__2014). The validation procedures of the employed FE model including comparisons with a broad range of test data are discussed in great detail in prior published work by the first and third authors (Elkady and Lignos 2015, 2018b) as well as an international blind analysis prediction contest on deep, wide-flange structural steel beam-columns (NIST_-A_TC_201요.

In brief, the considered steel columns utilize cross-section sizes ranging from W12 to W36, which represent typical member sizes for first story columns in steel frame buildings designed in high seismic regions of North America. The CFE models are subjected to both symmetric cyclic and monotonic loading coupled with constant compressive axial load demands ranging from, $P_{g} / P_{y e}$ of 0 to 0.75 .

\section{Observed Trends of the Component Model Parameters}

Prior work (Elkady and Lignos 2015, 2018b, c) underscores the influence of the web slenderness, $h / t_{w}$, the gravity-induced compressive axial load ratio, $P_{g} / P_{y e}$ and the member slenderness, $L_{b} / r_{y}$ ( $L_{b}$ is the column's unbraced length; $r_{y}$ is the radius of gyration in the 
This paper is published as: Lignos, D.G., Hartloper, A.R., Elkady, A., Deierlein, G.G., Hamburger, R. (2019). "Proposed updates to the ASCE 41 nonlinear modeling parameters for wide-flange steel columns in support of performance-based seismic engineering, Vol. 145(9), pp. 04019083, doi: 10.1061/(ASCE)ST.1943$541 X .0002353$

211 column cross-section's weak axis) on the hysteretic response of wide-flange steel columns.

212 Figure 3 depicts the influence of the above parameters on the deduced parameters of the firstcycle envelope curve of steel columns. The above geometric and loading parameters are selected because they were found to be statistically significant to the first cycle envelope and monotonic backbone input model parameters of a column (Elkady and Lignos 2018b, c). The data plots distinguish between available physical tests (termed as "Test Data") and the CFE simulation data (termed as "CFE Data"). The dashed straight lines shown in these figures only indicate the data trends between the column geometric $\left(h / t_{w}, L_{b} / r_{y}\right)$ and axial loading parameters $\left(P_{g} / P_{y e}\right)$ and the deduced parameters of a column's first-cycle envelope curve. The established linear trend lines are only used to facilitate the discussion herein. Referring to Fig. $3 a$, the pre-peak plastic rotation, $\theta_{p}^{*}$, decreases with increasing $h / t_{w}$ due to the earlier onset of local buckling-induced softening observed in more slender cross-sections. This is exacerbated with increasing $P_{g} / P_{y e}$ (see Fig. 3b). With increasing $L_{b} / r_{y}$, the cyclic strength deterioration is accelerated due to coupling of local and lateral torsional buckling (see Fig. 3c). Referring to Fig. 3b, the decreasing variance in $\theta_{p}^{*}$ with increasing $P_{g} / P_{y e}$ highlights the strong influence of this parameter on $\theta_{p}^{*}$, an effect that is not reflected in the ASCE 41-13 (ASCE 2014) guidelines.

Similar trends are found with respect to the post-peak plastic rotation, $\theta_{p c}^{*}$, although a larger scatter in the data is observed in this case. This is attributed to the higher dependency of $\theta_{p c}^{*}$ on the $L_{b} / r_{y}$ due to coupling of local and lateral torsional buckling in the post-peak response (Ozkula et al. 2017; Elkady and Lignos 2018a). Notably, the interdependency of $L_{b} / r_{y}$ and $h / t_{w}$ on the " $a$ " and " $b$ " ASCE 41-13 component model definitions is neglected. These two parameters are defined in Fig. $1 \mathrm{~b}$.

Referring to Fig. 1b, a common value that has been historically employed for the hardening slope in the post-yield range is $3 \%$ of the elastic stiffness or the respective structural component (ASCE 2014). Steel components subjected to cyclic loading harden due to combined isotropic and kinematic hardening. This combined hardening effect is dependent on the steel material type (Kanno 2016). For the employed model discussed herein (see Fig. 1) this effect can only be inherently represented by a hardening ratio, $a^{*}=M_{\text {max }}^{*} / M_{y}^{*}$. Figure $3 \mathrm{~d}$ shows the relation of $a^{*}$ with respect to $h / t_{w}$. From this figure, stocky columns (i.e., $h / t_{w} \approx 20$ ) can develop a maximum flexural strength, $M_{\max }^{*}$ approximately 1.6 times their effective yield strength, $M_{y}^{*}$, due to the delay of local buckling even at large lateral drift amplitudes. This is consistent with 
This paper is published as: Lignos, D.G., Hartloper, A.R., Elkady, A., Deierlein, G.G., Hamburger, R. (2019). "Proposed updates to the ASCE 41 nonlinear modeling parameters for wide-flange steel columns in support of performance-based seismic engineering, Vol. 145(9), pp. 04019083, doi: 10.1061/(ASCE)ST.1943541X.0002353

242

243

244

245

246

247

248

249

250

251

252

253

254

255

256

257

258

259

260

261

262

263

264

265

266

267

268

269

270

observations from full-scale experiments (Newell and Uang 2008). On the other hand, steel columns with seismically compact but slender cross-sections near the current compactness limits of highly ductile members (AISC 2016a) exhibit negligible hardening due to the early onset of geometric instabilities. This becomes more evident in cases that the compressive axial load demands are larger than $0.30 P_{y e}$. Referring to the input parameters of the monotonic backbone curve shown in Fig. 1b, similar trends hold true. In particular, there is a strong negative relation between $\theta_{p}$ and both $h / t_{w}$ and $P_{g} / P_{y e}$, as expected. The dependence of $\theta_{p}$ on $L_{b} / r_{y}$ is much less pronounced than that observed in the of $\theta_{p^{-}}^{*} L_{b} / r_{y}$ relation. This is due to the fact that member instabilities of wide-flange steel columns utilizing seismically compact cross-sections do not typically occur until after the onset of local buckling, which is strongly associated with a loss of lateral torsional rigidity of a wide-flange member (Elkady and Lignos 2018a). For further details, the reader is referred to Hartloper (2016).

\section{Description of Multiple Regression Model}

The most relevant parameters in predicting a wide-flange steel column's first-cycle and backbone curves are the web slenderness ratio, $h / t_{w}$ as defined in AISC-341-16 (AISC 2016a); the member slenderness ratio, $L_{b} / r_{y}$; and the gravity-induced compressive axial load ratio, $P_{g} / P_{y e}$. Accordingly, the proposed empirical multiple regression model is as follows,

$$
y=\beta_{o}\left(\frac{h}{t_{w}}\right)^{\beta_{1}} \cdot\left(\frac{L_{b}}{r_{y}}\right)^{\beta_{2}} \cdot\left(1-\frac{P_{g}}{P_{y e}}\right)^{\beta_{3}}+\varepsilon
$$

in which, $y$ is the predicted response parameter of interest; $\beta_{j}$ are the regression coefficients; and $\varepsilon$ is the error between the test and predicted responses. The goodness-of-fit for each regression equation can be partially evaluated based on the coefficient of determination, $R^{2}$, and coefficient of variation (COV). The $R^{2}$ and COV values are representative of the magnitude and level of scatter in $\varepsilon$, respectively. Although outside the scope of this paper, the reported $\mathrm{COV}$ values can facilitate the quantification of modeling uncertainties on the overall steel frame building seismic performance in a similar manner discussed in Liel et al. (2009) and Gokkaya et al. (2016).

Although the flange local slenderness, $b_{f} / 2 t_{f}$ can somewhat affect the response parameters, it was found to be collinear with $h / t_{w}$ for the range of hot-rolled cross-sections included in the steel column database (see Fig 3a). This argument may not hold true for built up cross-sections, 
This paper is published as: Lignos, D.G., Hartloper, A.R., Elkady, A., Deierlein, G.G., Hamburger, R. (2019). "Proposed updates to the ASCE 41 nonlinear modeling parameters for wide-flange steel columns in support of performance-based seismic engineering, Vol. 145(9), pp. 04019083, doi: 10.1061/(ASCE)ST.1943$541 X .0002353$

271 where the strong correlation between $b_{f} / 2 t_{f}$ and $h / t_{w}$ is not necessarily maintained. However, the focus on the present work is on beam-columns utilizing hot-rolled cross-sections.

Stepwise multiple regression analysis (Chatterjee and Hadi 2015) is used to determine the regression equations' coefficients. The statistical analysis of the regression models is presented in detail in the following section.

\section{Statistical Analysis of the Regression Models}

The quality of each regression model is evaluated based on the conditions of the Gauss-Markov theory (Chatterjee and Hadi 2015). In particular, three conditions are checked for each model: (1) the mean of the residuals is equal to zero; (2) the residuals have constant variance (i.e., homoscedasticity); and (3) no correlation is present among the residuals. Residuals were calculated for the plastic deformation parameters $\theta_{p}\left(\theta_{p}^{*}\right), \theta_{p c}\left(\theta_{p c}^{*}\right)$ the hardening ratios $\alpha\left(a^{*}\right)$ and the residual flexural strength, $M_{r}\left(M_{r}^{*}\right)$. The raw residual is utilized for this purpose, which is defined as the difference between the observed values minus the predicted ones from the developed regression equations. All statistical tests are conducted considering a significance level of $5 \%$ (i.e., $\alpha=0.05$ ). For brevity, only the statistical analysis of $\theta_{p}^{*}$ is presented herein. The reader is referred to Hartloper (2016) for further details regarding the rest of the input model parameters.

A Lilliefors test (Lilliefors 1967) is conducted on the residuals of the $\theta_{p}^{*}$ model. The resulting $p$-value of about 0.5 confirms the null hypothesis of normally-distributed residuals. This is supported by visual inspection of the quantile-quantile (i.e., QQ) plot (Chatterjee and Hadi 2015) shown in Fig. 4a. The markers falling close to the dashed line indicate that the residuals closely follow the normal distribution, as originally assumed in the null hypothesis.

The condition of mean of the residuals is assumed to be zero is evaluated through a $t$-test. Based on the residuals of the $\theta_{p}^{*}$ model, the test returned a $p$-value $\approx 1.00$, indicating that the residuals have a zero mean. The homoscedasticity of the residuals is visually checked based on the plot of residuals versus the predicted values. Referring to Fig. 4b, in general, the residuals have a constant variance over the range of predicted values.

Finally, the correlation between residuals and predictors is evaluated based on inspection of the partial residual plots (Fox 1991). The partial residual plot with respect to $P_{g} / P_{y e}$ is shown in Fig. 4c. A relationship is evident between these two parameters, as indicated by the dashed 
This paper is published as: Lignos, D.G., Hartloper, A.R., Elkady, A., Deierlein, G.G., Hamburger, R. (2019). "Proposed updates to the ASCE 41 nonlinear modeling parameters for wide-flange steel columns in support of performance-based seismic engineering, Vol. 145(9), pp. 04019083, doi: 10.1061/(ASCE)ST.1943541X.0002353

301

302

303

304

305

306

307

308

309

310

311

312

313

314

315

316

317

318

319

320

321

322

323

324

325

326

327

328

trend line. The regression equation generally underestimates the $\theta_{p}^{*}$ for high compressive axial load ratios (i.e., $P_{g} / P_{y e}>35 \%$ ), and overestimates in between. To preserve the form of the proposed equations for simplicity, and to ensure rational predictions for the pre-peak plastic rotation at moderate axial load levels, a limit of $\theta_{p}^{*} \leq 0.1 \mathrm{rad}$ is imposed to the respective equation. Similar restrictions are placed on the rest of the empirical equations where this issue is encountered.

Proposed Equations for Predicting Component Model Parameters for Wide Flange Steel Columns

This section provides equations to estimate each of the proposed component models' parameters (see Fig. 1). The dataset used to develop Eqs. (2) through Error! Reference source not found. comprised of structural steel cross sections made of ASTM A992 Gr. 50 steel (ASTM 2015) or equivalent steel material (i.e., $F_{y n}=345 \mathrm{MPa}$ ). The ranges of predictor variables in Eqs. (2) through Error! Reference source not found. are as follows: $3.71 \leq h / t_{w} \leq 57.5,38.4 \leq L_{b} / r_{y} \leq 120$, and $0.0 \leq P_{g} / P_{y e} \leq 0.75$.

\section{Flexural strength parameters}

The effective yield strength, $M_{y}^{*}$, is calculated based on the AISC-360-16 (AISC 2016b) P-M interaction equation adjusted for the effects of cyclic hardening as follows,

$$
M_{y}^{*}=\left\{\begin{array}{ll}
1.15 \cdot Z \cdot R_{y} \cdot F_{y n} \cdot\left(1-\frac{P_{g}}{2 P_{y e}}\right) & \text { if } P_{g} / P_{y e}<0.20 \\
1.15 \cdot Z \cdot R_{y} \cdot F_{y n} \cdot \frac{9}{8}\left(1-\frac{P_{g}}{P_{y e}}\right) & \text { if } P_{g} / P_{y e} \geq 0.20
\end{array},(\mathrm{COV}=0.10)\right.
$$

in which, $Z$ is the plastic section modulus of the wide-flange cross-section; $R_{y}$ is the expectedto-nominal yield stress ratio from Table A3.1 per AISC-341-16 (AISC 2016a); and $F_{y n}$ is the nominal yield stress of the steel material. Note that $M_{y}^{*}$ is the same for both the proposed monotonic and first-cycle envelope curves.

The peak flexural strength $M_{\max }^{(*)}$ can then be computed as $M_{\max }^{(*)}=a^{(*)} \cdot M_{y}^{*}$, where the hardening ratio parameters, $a$ (for the monotonic backbone) and $a^{*}$ (for the first-cycle envelope) are estimated using Eqs. (3) or (4), respectively. An upper bound of 1.3 is enforced to limit the amount of cyclic hardening in columns with stocky cross-sections undergoing low compressive axial load demands. This limit is rational for A992 Gr. 50 steel or equivalent steels (Kanno 2016; Sousa and Lignos 2017). The corresponding hardening ratios are as follows, 
This paper is published as: Lignos, D.G., Hartloper, A.R., Elkady, A., Deierlein, G.G., Hamburger, R. (2019). "Proposed updates to the ASCE 41 nonlinear modeling parameters for wide-flange steel columns in support of performance-based seismic engineering, Vol. 145(9), pp. 04019083, doi: 10.1061/(ASCE)ST.1943541X.0002353

$$
a=12.5 \cdot\left(\frac{h}{t_{w}}\right)^{-0.2} \cdot\left(\frac{L_{b}}{r_{y}}\right)^{-0.4} \cdot\left(1-\frac{P_{g}}{P_{y e}}\right)^{0.4} 1.0 \leq a \leq 1.3
$$

$$
\left(R^{2}=0.76, C O V=0.1\right)
$$

Expressed as a percentage of the effective yield strength, the column's residual flexural strength, $M_{r}$ or $M_{r}^{*}$, can be estimated by Eqs. (5) and Error! Reference source not found., respectively,

$$
\begin{aligned}
& a^{*}=9.5 \cdot\left(\frac{h}{t_{w}}\right)^{-0.4} \cdot\left(\frac{L_{b}}{r_{y}}\right)^{-0.16} \cdot\left(1-\frac{P_{g}}{P_{y e}}\right)^{0.2} 1.0 \leq a \leq 1.3 \\
& \left(R^{2}=0.87, \operatorname{COV}=0.07\right)
\end{aligned}
$$

$$
\begin{aligned}
& M_{r}=\left(0.5-0.4 \cdot \frac{P_{g}}{P_{y e}}\right) \cdot M_{y}^{*}(\operatorname{COV}=0.27) \\
& M_{r}^{*}=\left(0.4-0.4 \cdot \frac{P_{g}}{P_{y e}}\right) \cdot M_{y}^{*}(\operatorname{COV}=0.35)
\end{aligned}
$$

\section{Yield deformation}

The effective yield rotation, $\theta_{y}^{*}$, shall be deduced directly from the column's effective yield strength, $M_{y}^{*}$, and the elastic stiffness, $K_{e}$. Experiments (Lignos et al. 2016; Ozkula et al. 2017; Elkady and Lignos 2018a) suggest that the contribution of the shear deformations can reach up to $30 \%$ of the overall column's elastic deformation for standard building configurations. Therefore, the column's elastic stiffness $K_{e}$ can be computed in the same manner with the flexural stiffness of eccentrically braced frame link beams (Bech et al. 2015). In particular, $K_{e}=L^{2} K_{s} K_{b} /\left[2\left(K_{s}+K_{b}\right)\right]$ in which, the shear and flexural stiffness are $K_{s}=G A_{w} / L$ and $K_{b}=12 E I / L^{3}$, respectively. If the column is not in double curvature, then $K_{b}$ shall be adjusted accordingly; $E$ and $G$ are Young's and the shear modulus, respectively, of the steel material; $A_{w}$ is the web area of the wide-flange cross-section as defined in AISC-341-16 (AISC 2016a); $L$ is the column's length; $I$ is the moment of inertia of the cross-section with respect to its strong axis.

\section{Plastic deformation parameters}

The steel column's pre-peak plastic rotation $\left(\theta_{p}\right.$ or $\left.\theta_{p}^{*}\right)$ can be estimated as follows,

$$
\theta_{p}=294 \cdot\left(\frac{h}{t_{w}}\right)^{-1.7} \cdot\left(\frac{L_{b}}{r_{y}}\right)^{-0.7} \cdot\left(1-\frac{P_{g}}{P_{y e}}\right)^{1.6} \theta_{p} \leq 0.20 \mathrm{rad}
$$

$$
\left(R^{2}=0.89, \operatorname{COV}=0.39\right)
$$


This paper is published as: Lignos, D.G., Hartloper, A.R., Elkady, A., Deierlein, G.G., Hamburger, R. (2019). "Proposed updates to the ASCE 41 nonlinear modeling parameters for wide-flange steel columns in support of performance-based seismic engineering, Vol. 145(9), pp. 04019083, doi: 10.1061/(ASCE)ST.1943541X.0002353

$$
\theta_{p}^{*}=15 \cdot\left(\frac{h}{t_{w}}\right)^{-1.6} \cdot\left(\frac{L_{b}}{r_{y}}\right)^{-0.3} \cdot\left(1-\frac{P_{g}}{P_{y e}}\right)^{2.3} \theta_{p}^{*} \leq 0.10 \mathrm{rad}
$$

$$
\left(R^{2}=0.89, \operatorname{COV}=0.31\right)
$$

Similarly, the post-peak plastic deformation capacity $\left(\theta_{p c}\right.$ or $\left.\theta_{p c}^{*}\right)$, representative of the column's post-buckling behavior can be estimated as,

$$
\theta_{p c}=90 \cdot\left(\frac{h}{t_{w}}\right)^{-0.8} \cdot\left(\frac{L_{b}}{r_{y}}\right)^{-0.8} \cdot\left(1-\frac{P_{g}}{P_{y e}}\right)^{2.5} \theta_{p} \leq 0.30 \mathrm{rad}
$$

$$
\left(R^{2}=0.91, \operatorname{COV}=0.26\right)
$$

$$
\begin{aligned}
& \theta_{p c}^{*}=14 \cdot\left(\frac{h}{t_{w}}\right)^{-0.8} \cdot\left(\frac{L_{b}}{r_{y}}\right)^{-0.5} \cdot\left(1-\frac{P_{g}}{P_{y e}}\right)^{3.2} \theta_{p} \leq 0.10 \mathrm{rad} \\
& \left(R^{2}=0.78, \mathrm{COV}=0.42\right)
\end{aligned}
$$

The ultimate rotation $\left(\theta_{u l t}\right.$ or $\left.\theta_{u l t}^{*}\right)$, representative of the total chord-rotation at which a steel column loses its axial load carrying capacity, can be estimated as follows,

$$
\begin{aligned}
& \theta_{u l t}=0.15(\operatorname{COV}=0.46) \\
& \theta_{u l t}^{*}=0.08 \cdot\left(1-0.6 \cdot \frac{P_{g}}{P_{y e}}\right)(\operatorname{COV}=0.51)
\end{aligned}
$$

Table 1 summarizes the proposed component model parameters for typical column crosssections based on the procedures outlined in this paper. Based on these values, the ratio of the mean total plastic rotation between the monotonic backbone curve and the first-cycle envelope curve $\left(\theta_{u l t} / \theta_{u l t}^{*}\right)$ is about 2.6, which is consistent with prior experimental studies conducted on nominally identical column specimens (Suzuki and Lignos 2015, 2017; Lignos et al. 2016).

\section{Reference cumulative plastic rotation capacity}

An empirical relation is proposed to compute the reference energy dissipation capacity, $\Lambda$ of the modified IMK deterioration model (Ibarra et al. 2005; Lignos and Krawinkler 2011) for simulating explicitly the cyclic deterioration in strength and stiffness of steel columns in frame buildings with a concentrated plastic hinge model. For a particular test result, this parameter is calibrated by minimizing an objective function that consists of the integral of the square difference between the predicted and the measured moment over the accumulated plastic rotation. Referring to Figs. $2 \mathrm{c}$ and $2 \mathrm{~d}$, the simulated column response is based on these 
This paper is published as: Lignos, D.G., Hartloper, A.R., Elkady, A., Deierlein, G.G., Hamburger, R. (2019). "Proposed updates to the ASCE 41 nonlinear modeling parameters for wide-flange steel columns in support of performance-based seismic engineering, Vol. 145(9), pp. 04019083, doi: 10.1061/(ASCE)ST.1943541X.0002353

386

390

391

392

393

394

395

396

397

398

399

400

401

402

403

404

405

406

407

408

409

410

411

calibrations. The proposed equation for computing the $\Lambda_{\mathrm{s}}$ parameter, which controls the cyclic basic strength deterioration of a steel column is as follows,

The use of a single equation in this case is not possible because the influence of $P_{g} / P_{y e}$ on the rate of cyclic strength deterioration is not well captured. If a single equation were to be used, then the $\Lambda$ values would be under predicted at $P_{g} / P_{y e}$ ratios of $5 \%$ to $30 \%$, which are commonly seen in steel MRFs (Suzuki and Lignos 2014). This is not a controlling issue for stocky columns, where cyclic strength and stiffness deterioration is only a minor issue (Newell and Uang 2008). Equation (13) suggests that the influence of $P_{g} / P_{y e}$ on $\Lambda_{\mathrm{s}}$ is stronger when $P_{g} / P_{y e} \leq 35 \%$ than $P_{g} / P_{y e}>35 \%$. The reason is that in the former, for small axial load ratios, web local buckling is partially restrained because the neutral axis is typically in the web of the respective cross-section; while in the latter, the neutral axis is typically in the cross-section's flange; thus, the plate buckling resistance is only modestly influenced by $P_{g} / P_{y e}$.

Prior calibration studies for steel beams showed that distinguishing the response with multiple $\Lambda$ parameters (e.g., for different deterioration modes) does not necessarily increase the model accuracy (Lignos and Krawinkler 2011). In the case of wide-flange steel columns, it was found that the post-peak strength and unloading stiffness deterioration parameters $\Lambda_{\mathrm{c}}$ and $\Lambda_{\mathrm{k}}$, respectively, can be estimated as 0.9 times the value of $\Lambda_{\mathrm{s}}$.

\section{Comparison of Proposed Models with Test Data and ASCE 41-13 Modeling Guidelines}

The sufficiency of the proposed modeling recommendations in predicting the first cycle and monotonic backbone curves for steel wide-flange columns is demonstrated through meaningful comparisons with representative test data. The parameters $\theta_{p}^{*}, \theta_{p c}^{*}$, that define the plastic deformation capacity of a steel column's first-cycle envelope curve are plotted against their corresponding test/simulation values used in the multiple regression models in Figs. 5a and 5b, 
This paper is published as: Lignos, D.G., Hartloper, A.R., Elkady, A., Deierlein, G.G., Hamburger, R. (2019). "Proposed updates to the ASCE 41 nonlinear modeling parameters for wide-flange steel columns in support of performance-based seismic engineering, Vol. 145(9), pp. 04019083, doi: 10.1061/(ASCE)ST.1943$541 X .0002353$

412 respectively. Each of the model parameters show a relatively good fit reflected by the data 413 points clustered close to the dashed line. This is also supported by the corresponding $R^{2}$ values.

414 Referring to Figs. 5a and b, the increase in the scatter with larger response parameter values is due to the constant variance in the residuals in the log-log domain (i.e., the ratio of the errorto-predicted magnitude ratio is constant). Consequently, the error increases as the absolute value of the response parameter increases. Same observations hold true for the rest of the input model parameters with reference to Figs. 1 and 2. For this reason, upper bound limits are imposed in the predicted parameters. Same observations hold true for the $\Lambda$ values of most column cross-sections as shown in Fig. 5d.

Figure 6 shows the response of a number of tested steel columns subjected to monotonic and symmetric cyclic loading. In an attempt to provide confidence on the proposed modeling recommendations, superimposed in the same figure, are the component models based on the procedures proposed in this paper, as well as those from ASCE 41-13 (ASCE 2014) provisions. The following observations may be made:

- The ASCE 41-13 model ignores the shear deformation contributions in the column's effective stiffness, $K_{e}$ calculations; thus $K_{e}$ is underpredicted by about $30 \%$, on average. In that sense, the current ASCE 41-17 refined recommendations are substantiated.

- Referring to Fig. 6a the proposed steel column monotonic backbone represents fairly well the experimental data including the post-peak plastic deformation range. The observed differences in the predicted versus the measured effective yield strength are due to the material variability associated with the expected-to-measured yield stress.

- Referring to Figs. $6 \mathrm{~b}$ and $6 \mathrm{~d}$, the proposed first-cycle envelope curve represents relatively well the measured response of steel columns regardless of the $h / t_{w}$ and the applied $P_{g} / P_{y e}$. On the other hand, the ASCE 41 component model overestimates the pre-peak plastic deformation of steel columns subjected to $P_{g} / P_{y e}=0.20$ (see Fig. 6b). This is attributed to the fact that the ASCE 41 component model does not capture the cross-section local slenderness effects on the pre-peak plastic deformation parameter " $a$ " as defined in the ASCE 41 modeling recommendations. In addition, the ASCE 41 component model does not directly capture the effect of $L_{b} / r_{y}$ on parameter " $a$ ".

- Referring to Figs. 6c and 6d, steel columns that utilize cross sections within the limits of highly ductile members as per AISC-341-16 (AISC 2016a) and subjected to $P_{g} / P_{y e}$ $=0.50$ (i.e., $P_{g} / P_{C L}>0.50$ ) have an appreciable plastic deformation capacity that is 
This paper is published as: Lignos, D.G., Hartloper, A.R., Elkady, A., Deierlein, G.G., Hamburger, R. (2019). "Proposed updates to the ASCE 41 nonlinear modeling parameters for wide-flange steel columns in support of performance-based seismic engineering, Vol. 145(9), pp. 04019083, doi: 10.1061/(ASCE)ST.1943541X.0002353

significantly underestimated by the ASCE 41-13 component model that treats such members as force-controlled elements (i.e., no plastic deformation capacity). This issue is elaborated in a subsequent section.

- In contrast to the ASCE 41 model, the gradual reduction in the column's flexural strength in the post-peak response is captured relatively well by the proposed model.

\section{Modeling Recommendations for Columns Subjected to Bidirectional Lateral Loading}

Columns in steel frame buildings undergo biaxial bending demands during 3-dimensional ground shaking. Figure 7 shows a comparison of the normalized first-cycle envelope curves for two nominally identical W24x84 columns, subjected to unidirectional and bidirectional loading histories (Elkady and Lignos 2018a) coupled with a constant compressive axial load. Notably, the plastic deformation capacity of both specimens is virtually the same. Hence, Eqs. (7) to (13) should be used without any adjustment due to the biaxial bending effects. On the other hand, the effective flexural strength parameters of the first-cycle and monotonic backbone curves should be adjusted by modifying Eq. (2) to account for the axial load-biaxial bending $\left(\mathrm{P}-\mathrm{M}_{\mathrm{x}}-\mathrm{M}_{\mathrm{y}}\right)$ interaction. The AISC 360-16 (AISC 2016b) interaction equations shall be employed for this purpose. It should be stated that this observation may not necessarily hold true for end steel MRF columns experiencing axial load fluctuations synchronized with bidirectional lateral loading histories. This issue shall be carefully examined in future related studies.

\section{Modeling Recommendations for End Columns}

End columns in steel MRFs may experience large variations in their axial load demands due to dynamic overturning effects (Suzuki and Lignos 2014). These variations, about the gravityinduced compressive load $P_{g}$, can reach about $\pm 35 \%$ of $P_{y e}$ (Suzuki and Lignos 2014). Figure 8 depicts the average first-cycle envelope of both stocky and slender column cross-sections subjected to gravity-induced axial load $P_{g}$, plus a transient component $P$ due to dynamic overturning effects. For instance, Fig. 8a shows a 4000mm long W24x233 column subjected to a gravity-induced axial load ratio of $P_{g} / P_{y e}=0.15$ and a transient axial load ratio varying with respect to the gravity-induced offset from $P / P_{y e}=-0.15$ in tension to $P / P_{y e}=0.75$ in compression while the lateral drift increases up to 0.07 rads. Although the peak compressive 
This paper is published as: Lignos, D.G., Hartloper, A.R., Elkady, A., Deierlein, G.G., Hamburger, R. (2019). "Proposed updates to the ASCE 41 nonlinear modeling parameters for wide-flange steel columns in support of performance-based seismic engineering, Vol. 145(9), pp. 04019083, doi: 10.1061/(ASCE)ST.1943541X.0002353

axial load demand is $75 \% P_{y e}$ (well above $50 \% P_{C L}$ ) in both columns shown in Fig. 8, stocky cross-sections $\left(h / t_{w}<10\right)$ are able to sustain considerable inelastic deformation demands without noticeable strength deterioration (see Fig. 8a) due to local and/or member instabilities (Newell and Uang 2008). Figure 8b, shows the first-cycle moment-rotation envelope of a W16x89 column, which comprises a slender but seismically compact cross-section according to the AISC-341-16 (AISC 2016a) seismic provisions. This member experiences local buckling-induced softening at much smaller inelastic deformations than the W24x233 column. However, the associated inelastic deformation capacity of the W16x89 is still appreciable despite the excessive compressive axial load ratio of $P / P_{y e}=0.75$ due to the combined gravity and transient axial load demands coupled with the imposed lateral drift history.

Referring to Figure 8, unlike the ASCE 41 component model, the proposed model seems to predict reasonably well the column's plastic deformation capacity by just considering the gravity-induced load component $\left(P_{g} / P_{y e}\right)$. Same observations hold true for the rest of the data. In that respect, columns experiencing varying axial load and lateral drift demands may be modeled based on the procedures outlined in this paper considering only the gravity-induced axial load ratio, $P_{g} / P_{y e}$ and neglecting the transient effects. Ideally, numerical models that explicitly capture the axial force-bending interaction within the cross-section should be employed for this purpose (e.g., Krishnan 2010; Suzukuki and Lignos_2017; _ Do and Filippou 2018; Kolwankar_et_al._2018). Global instability modes shall also be considered within a

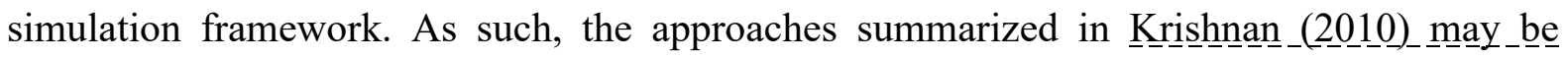
employed for frame analyses not involving CFE models. However the coupling of local and

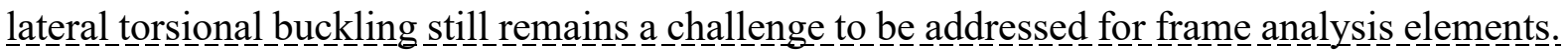

\section{Proposed Updates for Force-Controlled Elements}

Referring to Fig. 9, steel columns with seismically compact cross-sections (i.e., $h / t_{w}<43$ ) have considerable pre- and post- peak plastic deformation capacities regardless of the applied axial compressive load ratio. This is also evident from Fig. $2 \mathrm{~b}$ for the entire column data set as well as prior related studies by the first and third authors (Elkady and Lignos 2018b). Accordingly, it is recommended that the ASCE $41-13$ force-controlled limit of $50 \% P_{C L}$ be relaxed to $60 \%$ $P_{y e}$ for wide-flange steel columns with $h / t_{w} \leq 43$ and $L_{b} / r_{y} \leq 120$. At compressive axial load demands near $P / P_{y e}>60 \%$, steel columns may be very close to their lower-bound 
This paper is published as: Lignos, D.G., Hartloper, A.R., Elkady, A., Deierlein, G.G., Hamburger, R. (2019). "Proposed updates to the ASCE 41 nonlinear modeling parameters for wide-flange steel columns in support of performance-based seismic engineering, Vol. 145(9), pp. 04019083, doi: 10.1061/(ASCE)ST.1943$541 X .0002353$

503 compressive strength, $P_{C L}$, especially in the presence of geometric imperfections due to 504 fabrication/erection. This substantiates the refined limit for force-controlled column elements according to the ASCE 41-17 standard.

\section{Conclusions}

507 This paper provides comprehensive recommendations for nonlinear modeling of wide-flange steel columns for performance-based seismic assessment of new and existing steel frame buildings. Two sets of empirical parameters for concentrated hinge models are proposed. The new model parameters are calibrated to testing and high-fidelity continuum finite element analyses of wide-flange steel columns. The empirical formulations predict the monotonic and

512 first-cycle envelope curves of wide flange steel columns in their pre- and post-peak nonlinear response and can be directly used in nonlinear dynamic and static analysis procedures, respectively. Recommendations on how to explicitly simulate the cyclic deterioration in strength and stiffness of steel columns are also provided through the calibration of a widely used phenomenological deterioration model for frame analysis studies. The proposed firstcycle envelope curves are directly compared with the ASCE 41 component model for steel columns. The main findings are summarized as follows:

- The effective yield strength $M_{y}^{*}$ used in both the first-cycle envelope and monotonic backbone curves is, on average, 1.15 times the expected plastic resistance of steel columns reduced by the effects of the gravity induced axial load ratio based on the AISC-360-16 (AISC 2016b) uniaxial or biaxial bending-axial load interaction equations for unidirectional or bidirectional lateral loading, respectively.

- The test data suggest that shear deformations may contribute up to $30 \%$ to the effective elastic stiffness, $K_{e}$ of a steel column. Therefore, both flexural and shear deformations shall be considered in the elastic stiffness computations of steel columns.

- The axial load ratio, $P_{g} / P_{y e}$, is the primary contributor to the pre-peak plastic rotation, $\theta_{p}^{(*)}$ post-peak plastic rotation, $\theta_{p c}^{(*)}$, the post-yield hardening ratio $a^{(*)}=M_{\max }^{(*)} / M_{y}^{*}$ and the deterioration parameter $\Lambda$ of hot-rolled wide flange steel columns, followed by the cross-section's web local slenderness, $h / t_{w}$. Of somewhat importance is the member slenderness ratio, $L_{b} / r_{y}$ especially in the post-peak column response due to coupling of local and lateral torsional buckling. The ASCE 41-13 component model for 
This paper is published as: Lignos, D.G., Hartloper, A.R., Elkady, A., Deierlein, G.G., Hamburger, R. (2019). "Proposed updates to the ASCE 41 nonlinear modeling parameters for wide-flange steel columns in support of performance-based seismic engineering, Vol. 145(9), pp. 04019083, doi: 10.1061/(ASCE)ST.1943541X.0002353

steel columns does not directly capture these effects on the pre-peak plastic deformation parameter " $a$ ".

- The ratio of the mean total plastic rotation of a column's monotonic backbone curve to that of its first-cycle envelope curve is about 2.6.

- The ultimate rotation, $\theta_{\text {ult }}$ at which a steel column losses its axial load carrying capacity under cyclic loading is strongly influenced by $P_{g} / P_{y e}$ and it is on average 2 to 3 times less than that of the same column subjected to monotonic loading.

- Although bidirectional lateral loading has an apparent effect on the column's effective flexural strength $M_{y}^{*}$, it does not practically influence the column's plastic deformation capacity. However, this observation shall be examined carefully for end steel MRF columns experiencing axial load fluctuations due to dynamic overturning effects synchronized with bidirectional lateral loading histories.

- It was found that end columns subjected to varying axial load demands can be modeled reasonably well by only considering $P_{g} / P_{y e}$ and neglecting the transient axial load component due to dynamic overturning effects. However, additional nonlinear building simulations are required to further validate this statement.

- Data from experiments and corroborating finite element analyses suggests that steel columns with cross sections within the limits of highly ductile members as per AISC341-16 (AISC 2016a) have an appreciable plastic deformation capacity even in cases that $P_{g} / P_{C L}>0.50$. Accordingly, it is recommended that the ASCE 41-13 forcecontrolled limit of $50 \% P_{C L}$ be relaxed to $60 \% P_{y e}$ for wide flange steel columns with $h / t_{w} \leq 43$ and $L_{b} / r_{y} \leq 120$. In that respect, the adopted change in the recent ASCE 4117 provisions is deemed to be rational.

The conclusions of this paper are based on testing data and continuum finite element analyses of a wide range of hot-rolled column cross-sections made of A992 Gr. 50 steel or equivalent. The proposed recommendations shall be used with caution when built-up column crosssections are employed. Comprehensive system level studies should be conducted to further quantify the influence of the proposed modeling recommendations on the overall seismic behavior of steel frame buildings. For selected case study steel frame buildings, such studies have been conducted and are summarized in Hamburger et al. (2017). 
This paper is published as: Lignos, D.G., Hartloper, A.R., Elkady, A., Deierlein, G.G., Hamburger, R. (2019). "Proposed updates to the ASCE 41 nonlinear modeling parameters for wide-flange steel columns in support of performance-based seismic engineering, Vol. 145(9), pp. 04019083, doi: 10.1061/(ASCE)ST.1943541X.0002353

563

564

565

566

567

568

569

570

571

572

573

574

575

576

577

578

579

580

581

582

583

584

585

586

587

588

589

590

591

592

593

594

595

596

\section{Acknowledgements}

The work forming the basis for this publication was conducted pursuant to a contract with the National Institute of Standards and Technology (Contract No. 1140-22-431). The substance of such work is dedicated to the public. The authors are solely responsible for the accuracy of statements or interpretations contained in this publication. No warranty is offered with regard to the results, findings and recommendations contained herein, either by the National Institute of Standards and Technology, or the Applied Technology Council, its directors, members or employees. These organizations and individuals do not assume any legal liability or responsibility for the accuracy, completeness, or usefulness of any of the information, product or processes included in this publication. The authors gratefully acknowledge co-authors and project review panel of the NIST project; Jon Heintz, Ayse Hortacsu, Veronica Cedillos and ATC colleagues for managing the project and editing the final guidelines; and Steven L. McCabe and colleagues at NIST for their input and guidance throughout the project development process. Additional funding for the third author was provided by the Swiss National Science Foundation (Project No. 200021_169248). Any opinions expressed in the paper are those of the authors and do not necessarily reflect the views of sponsors.

\section{References}

ABAQUS. (2014). “ABAQUS user's manual.” Version 6.14, Providence, R.I.

AISC. (2016a). Seismic provisions for structural steel buildings, ANSI/AISC 341-16. American Institute of Steel Construction, Chicago, Illinois, United States.

AISC. (2016b). Specification for structural steel buildings, ANSI/AISC 360-16. American Institute of Steel Construction, Chicago, Illinois, United States.

Armstrong, P.J., Frederick, C.O. (1966). "A mathematical representation of the multiaxial bauschinger effect." Technical Report No. RD/B/N 731, Berkeley Nuclear Laboratories, Berkeley, California.

ASCE. (2014). Seismic evaluation and retrofit of existing buildings, American Society of Civil Engineers, Reston, Virginia.

ASCE. (2017a). Minimum design loads for buildings and other structures, American Society of Civil Engineers, Reston, Virginia.

ASCE. (2017b). Seismic evaluation and retrofit of existing buildings, American Society of Civil Engineers, Reston, Virginia.

ASTM. (2015). "Standard specification for structural steel shapes.” ASTM A992/A992M-11.

West Conshohocken, PA: ASTM.

ATC. (1997). Guidelines and commentary for seismic rehabilitation of buildings, FEMA 
This paper is published as: Lignos, D.G., Hartloper, A.R., Elkady, A., Deierlein, G.G., Hamburger, R. (2019). "Proposed updates to the ASCE 41 nonlinear modeling parameters for wide-flange steel columns in support of performance-based seismic engineering, Vol. 145(9), pp. 04019083, doi: 10.1061/(ASCE)ST.1943541X.0002353

273/274. Federal Emergency Management Agency, Washington, DC.

Bech, D., Tremayne, B., and Houston, J. (2015). "Proposed changes to steel column evaluation criteria for existing buildings." Proceedings ATC/SEI 2nd Conference on Improving the Seismic Performance of Existing Buildings and Other Structures, San Francisco, California, United States, 255-272.

Chaboche, J.L. (1989). "Constitutive equations for cyclic plasticity and cyclic viscoplasticity." International Journal of Plasticity, 5(3), 247-302.

Chatterjee, S., and Hadi, A. S. (2015). Regression analysis by example. John Wiley \& Sons.

Chen, Y. Y., Niu, L., and Cheng, X. (2014). "Hysteretic behaviour of H steel columns with large width-thickness ratios under bi-axis moments." Proceedings 10th National Conference on Earthquake Engineering (10NCEE), 21-25, Anchorage, Alaska, USA.

Cheng, X., Chen, Y., and Pan, L. (2013). "Experimental study on steel beam-columns composed of slender H-sections under cyclic bending." Journal of Constructional Steel Research, 88, 279-288.

Deierlein, G. G., Bono, S., Malley, J., O., Mazzoni, S., and Uang, C.-M. (2017). Guidelines for nonlinear structural analysis for design of buildings: Part IIa - Steel moment frames, Report No. NIST GCR 17-917-46v2, National Institute of Standards and Technology (NIST), U.S. Department of Commerce, Washington, DC (https://doi.org/10.6028/NIST.GCR.17-91746v2).

Deierlein, G. G., Lignos, D. G., Bono, S., and Kanvinde, A. (2018). "Guidelines on nonlinear dynamic analysis for steel moment frames." Proceedings 11th National Conference in Earthquake Engineering, Earthquake Engineering Research Institute (EERI), Los Angeles.

Deierlein, G. G., Reinhorn, A. M., and Willford, M. R. (2010). Nonlinear structural analysis for seismic design, NEHRP Seismic Design Technical Brief No. 4, NEHRP Seismic Design Technical Brief No. 4, National Institute of Standards and Technology, Gaithersburg, MD. Do, T. N., and Filippou, F. C. (2018). "A damage model for structures with degrading response.” Earthquake Engineering \& Structural Dynamics, 47(2), 311-332.

Elkady, A., and Lignos, D. G. (2015). "Analytical investigation of the cyclic behavior and plastic hinge formation in deep wide-flange steel beam-columns." Bulletin of Earthquake Engineering, 13(4), 1097-1118.

Elkady, A., and Lignos, D. G. (2018a). "Full-scale testing of deep wide-flange steel columns under multiaxis cyclic loading: Loading sequence, boundary effects, and lateral stability bracing force demands." ASCE Journal of Structural Engineering, 144(2), 04017189.

Elkady, A., and Lignos, D. G. (2018b). "Improved seismic design and nonlinear modeling recommendations for wide-flange steel columns." ASCE Journal of Structural Engineering, 144(9), 04018162.

Elkady, A., Ghimire, S., and Lignos, D.G. (2018c). "Fragility curves for wide-flange steel columns and implications on building-specific earthquake-induced loss assessment." Earthquake Spectra (in-press).

Elkady, A., and Lignos, D.G. (2017). "Full-scale cyclic testing of deep slender wide-flange steel beam-columns under unidirectional and bidirectional lateral drift demands." Proceedings 16th World Conference on Earthquake Engineering (16WCEE), International 
This paper is published as: Lignos, D.G., Hartloper, A.R., Elkady, A., Deierlein, G.G., Hamburger, R. (2019). "Proposed updates to the ASCE 41 nonlinear modeling parameters for wide-flange steel columns in support of performance-based seismic engineering, Vol. 145(9), pp. 04019083, doi: 10.1061/(ASCE)ST.1943541X.0002353

Association of Earthquake Engineering, Santiago, Chile.

FEMA. (1997a). NEHRP Guidelines for the seismic rehabilitation of buildings. Report FEMA273, Federal Emergency Management Agency, Washington, DC.

FEMA. (1997b). NEHRP Commentary on the guidelines for the seismic rehabilitation of buildings. Report FEMA-274, Federal Emergency Management Agency, Washington, DC FEMA. (2000). State of the art report on connection performance. Report FEMA-355D, Federal Emergency Management Agency, Washington, DC.

FEMA. (2009). Effects of strength and stiffness degradation on seismic response. Report No. FEMA P440A, Federal Emergency Management Agency, Washington, DC.

Fox, J. (1991). Regression Diagnostics: An Introduction. SAGE.

Gokkaya, B. U., Baker, J. W., and Deierlein, G. G. (2016). "Quantifying the impacts of modeling uncertainties on the seismic drift demands and collapse risk of buildings with implications on seismic design checks." Earthquake Engineering \& Structural Dynamics, 45(10), 1661-1683.

Hamburger, R., Deierlein, G., Lehman, D., Lowes, L., Shing, B., Van de Lindt, J., Lignos, D., and Hortacsu, A. (2016). "ATC-114 next-generation hysteretic relationships for performance-based modeling and analysis." Proceedings of the SEAOC Convention, Structural Engineers Association of California.

Hamburger, R. O., Deierlein, G. G., Lehman, D. E., Lignos, D., G., Lowes, L. N., Pekelnicky, R. G., Shing, P.-S. B., Somers, P., and Van de Lindt, J. W. (2017). Recommended modeling parameters and acceptance criteria for nonlinear analysis in support of seismic evaluation, retrofit, and design, Report No. NIST GCR 17-917-45, National Institute of Standards and Technology (NIST), U.S. Department of Commerce, Washington, DC (https://doi.org/10.6028/NIST.GCR.17-917-45).

Hartloper, A. R. (2016). "Updates to the ASCE-41-13 nonlinear modelling provisions for performance-based seismic assessment of new and existing steel moment resisting frames." Master Thesis, McGill University, Montreal, Quebec, Canada.

Haselton, C. B., Baker, J. W., Stewart, J. P., Whittaker, A. S., Luco, N., Fry, A., Hamburger, R. O., Zimmerman, R. B., Hooper, J. D., Charney, F. A., and Pekelnicky, R. G. (2017). "Response history analysis for the design of new buildings in the NEHRP provisions and ASCE/SEI 7 standard: Part I - overview and specification of ground motions." Earthquake Spectra, 33(2), 373-395.

Ibarra, L. F., Medina, R. A., and Krawinkler, H. (2005). "Hysteretic models that incorporate strength and stiffness deterioration." Earthquake Engineering \& Structural Dynamics, 34(12), 1489-1511.

Kanno, R. (2016). "Advances in steel materials for innovative and elegant steel Structures in Japan-A review." Structural Engineering International, 26(3), 242-253.

Kolwankar, S., Kanvinde, A., Kenawy, M., Lignos, D.G., Kunnath, S. (2018). "Simulating local buckling-induced softening in steel members using an equivalent nonlocal material model in displacement-based fiber elements." ASCE Journal of Structural Engineering, 144(10), 04018192.

Krawinkler, H. (2009). "Loading histories for cyclic tests in support of performance assessment 
This paper is published as: Lignos, D.G., Hartloper, A.R., Elkady, A., Deierlein, G.G., Hamburger, R. (2019). "Proposed updates to the ASCE 41 nonlinear modeling parameters for wide-flange steel columns in support of performance-based seismic engineering, Vol. 145(9), pp. 04019083, doi: 10.1061/(ASCE)ST.1943541X.0002353

of structural components." Proceedings 3rd International Conference on Advances in Experimental Seismic Engineering, Pacific Earthquake Engineering Research Center Annual Conference (PEER), San Francisco, California.

Krawinkler, H., Zohrei, M., Irvani, B. L., Cofie, N., and Tamjed, H. H. (1983). Recommendation for experimental studies on the seismic behavior of steel components and materials. Report No. 61, The John A. Blume Earthquake Engineering Center, Stanford University, Stanford, California.

Krishnan, S. (2010). "Modified elastofiber element for steel slender column and brace modeling." ASCE Journal of Structural Engineering, 136(11), 1350-1366.

LATBSDC. (2017). "An alternative procedure for seismic analysis and design of tall buildings located in the Los Angeles region, 2017 Edition." Los Angeles Tall Building Structural Design Council (http://www.tallbuildings.org/).

Liel, A. B., Haselton, C. B., Deierlein, G. G., and Baker, J. W. (2009). "Incorporating modeling uncertainties in the assessment of seismic collapse risk of buildings." Structural Safety, 31(2), 197-211.

Lignos, D. G., Cravero, J., and Elkady, A. (2016). "Experimental investigation of the hysteretic behavior of wide-flange steel columns under high axial load and lateral drift demands." Proceedings 11th Pacific Structural Steel Conference, Shanghai, China.

Lignos, D. G., and Krawinkler, H. (2011). "Deterioration modeling of steel components in support of collapse prediction of steel moment frames under earthquake loading." ASCE Journal of Structural Engineering, 137(11), 1291-1302.

Lilliefors, H. W. (1967). "On the Kolmogorov-Smirnov test for normality with mean and variance unknown." Journal of the American Statistical Association, 62(318), 399-402.

MacRae, G. A., Carr, A. J., and Walpole, W. R. (1990). "The seismic response of steel frames." $\mathrm{PhD}$ Thesis, University of Canterbury, Christchurch, New Zealand.

Maison, B. F., and Speicher, M. S. (2016). "Loading protocols for ASCE 41 backbone curves." Earthquake Spectra, 32(4), 2513-2532.

Nakashima, M., Takanashi, K., and Kato, H. (1990). "Test of steel beam-columns subject to sidesway." ASCE Journal of Structural Engineering, 116(9), 2516-2531.

Newell, J., and Uang, C.-M. (2008). "Cyclic behavior of steel wide-flange columns subjected to large drift." ASCE Journal of Structural Engineering, 134(8), 1334-1342.

NIST-ATC. (2018). "NIST-ATC blind prediction contest on deep, wide-flange structural steel beam-columns." Web Page: https://www.atcouncil.org/atc-106-blind-contest.

Ozkula, G., Harris, J., and Uang, C.-M. (2017). “Observations from cyclic tests on deep, wideflange beam-columns.” Engineering Journal, 54(1), 45-59.

PEER. (2017). Guidelines for performance-based seismic design of tall buildings, PEER Report 2017/06. Pacific Earthquake Engineering Research Center, University of California, Berkeley.

PEER/ATC. (2010). Guidelines for performance-based seismic design of Tall Buildings. Report No. ATC 72-1, Pacific Earthquake Engineering Research Center, University of California, Berkeley.

Sivaselvan, M. V. (2013). "Hysteretic models with stiffness and strength degradation in a 
This paper is published as: Lignos, D.G., Hartloper, A.R., Elkady, A., Deierlein, G.G., Hamburger, R. (2019). "Proposed updates to the ASCE 41 nonlinear modeling parameters for wide-flange steel columns in support of performance-based seismic engineering, Vol. 145(9), pp. 04019083, doi: 10.1061/(ASCE)ST.1943$541 X .0002353$

mathematical programming format." International Journal of Non-Linear Mechanics, 51, $10-27$.

Sousa, A. C., and Lignos, D. G. (2017). On the inverse problem of classic nonlinear plasticity models-An application to cyclically loaded structural steels. Technical Report No. 231968, Resilient Steel Structures Laboratory (RESSLab), École Polytechnique Fédérale de Lausanne, Lausanne.

Suzuki, Y., and Lignos, D. G. (2014). "Development of loading protocols for experimental testing of steel columns subjected to combined lateral drift and high axial load." Proceedings 10th National Conference on Earthquake Engineering (10th NCEE), Anchorage, Alaska, United States.

Suzuki, Y., and Lignos, D. G. (2015). "Large scale collapse experiments of wide flange steel beam-columns." Proceedings 8th International Conference on Behavior of Steel Structures in Seismic Areas (STESSA), Shanghai, China.

Suzuki, Y., and Lignos, D. G. (2017). "Collapse behavior of steel columns as part of steel frame buildings: Experiments and numerical models." Proceedings 16th World Conference of Earthquake Engineering, Santiago, Chile.

Voce, E. (1948). "The relationship between the stress and strain for homogeneous deformation." Journal of the Institute of Metals, 74, 537-562. 
This paper is published as: Lignos, D.G., Hartloper, A.R., Elkady, A., Deierlein, G.G., Hamburger, R. (2019). "Proposed updates to the ASCE 41 nonlinear modeling parameters for wide-flange steel columns in support of performance-based seismic engineering, Vol. 145(9), pp. 04019083, doi: 10.1061/(ASCE)ST.1943541X.0002353 
Table 1. Deterioration modeling parameters for first-cycle curve and monotonic backbone for selected steel wide-flange column crosssections [values calculated assuming $L_{b}=4500 \mathrm{~mm}, F_{y n}=345 \mathrm{MPa}$ (A992 Gr. 50 steel)]

\begin{tabular}{|c|c|c|c|c|c|c|c|c|c|c|c|c|c|c|c|c|}
\hline \multirow[t]{2}{*}{ Section } & \multirow{2}{*}{$\frac{h}{t_{w}}$} & \multirow{2}{*}{$\frac{L_{b}}{r_{y}}$} & \multicolumn{7}{|c|}{$P_{g} / P_{y e}=0.20$} & \multicolumn{7}{|c|}{$P_{g} / P_{y e}=0.50$} \\
\hline & & & $a$ & $\theta_{p}$ & $\theta_{p c}$ & $a^{*}$ & $\theta_{p}{ }^{*}$ & $\theta_{p c}{ }^{*}$ & $\Lambda_{\mathrm{s}}$ & $a$ & $\theta_{p}$ & $\theta_{p c}$ & $a^{*}$ & $\theta_{p}{ }^{*}$ & $\theta_{p c}{ }^{*}$ & $\Lambda_{\mathrm{s}}$ \\
\hline W33 3318 & 28.7 & 47.8 & 1.244 & 0.046 & 0.159 & 1.278 & 0.013 & 0.068 & 0.83 & 1.031 & 0.022 & 0.049 & 1.164 & 0.004 & 0.015 & 0.03 \\
\hline W27x 235 & 26.2 & 53.2 & 1.214 & 0.049 & 0.157 & 1.300 & 0.015 & 0.069 & 0.96 & 1.006 & 0.023 & 0.049 & 1.186 & 0.005 & 0.015 & 0.04 \\
\hline W24x146 & 33.2 & 58.9 & 1.111 & 0.031 & 0.120 & 1.166 & 0.010 & 0.054 & 0.55 & 1.000 & 0.015 & 0.037 & 1.061 & 0.003 & 0.012 & 0.02 \\
\hline W24x84 & 45.9 & 90.9 & 1.000 & 0.013 & 0.065 & 1.000 & 0.005 & 0.034 & 0.22 & 1.000 & 0.006 & 0.020 & 1.000 & 0.002 & 0.007 & 0.01 \\
\hline W14x370 & 6.9 & 41.5 & 1.300 & 0.200 & 0.300 & 1.300 & 0.100 & 0.100 & 3.00 & 1.300 & 0.200 & 0.172 & 1.300 & 0.045 & 0.050 & 1.09 \\
\hline W14x233 & 10.7 & 43.2 & 1.300 & 0.200 & 0.300 & 1.300 & 0.065 & 0.100 & 3.00 & 1.300 & 0.124 & 0.117 & 1.300 & 0.022 & 0.035 & 0.38 \\
\hline
\end{tabular}




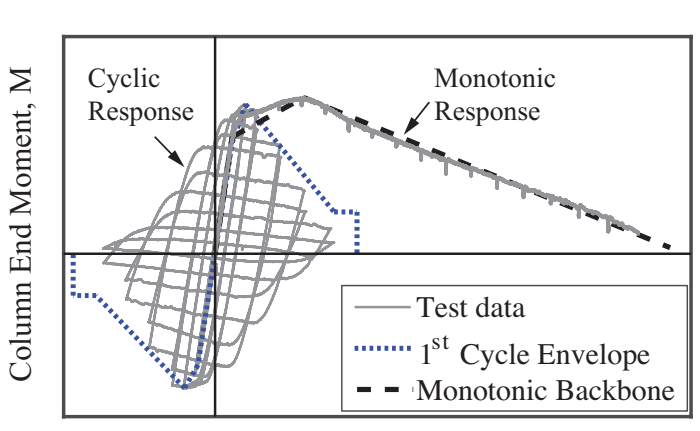

Chord Rotation, $\theta$

(a)

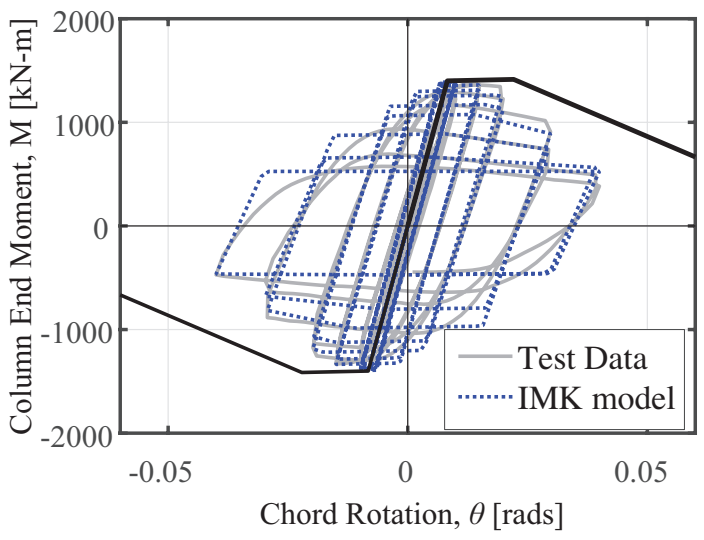

(c)

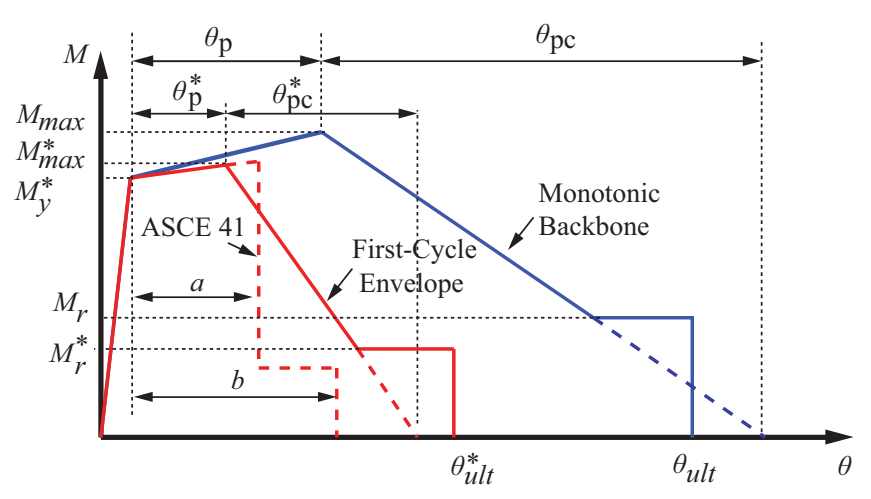

(b)

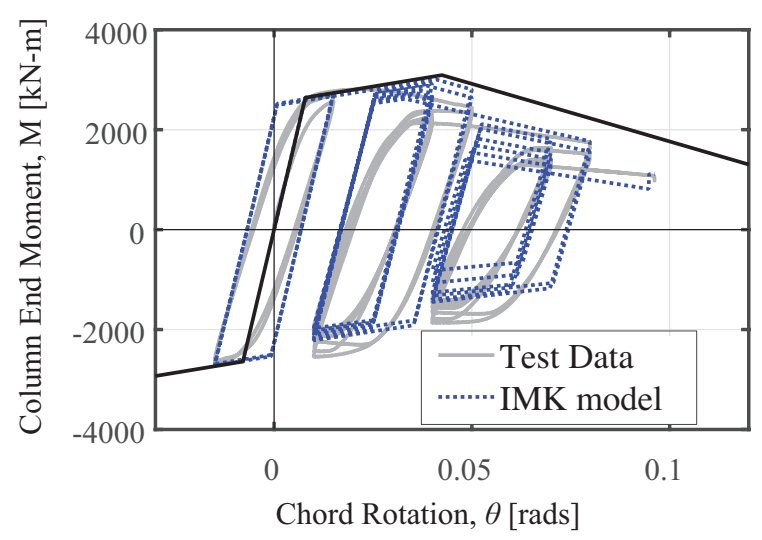

(d)

Fig. 1. Steel column component model definitions and illustrations of hysteretic deterioration model [Experimental data from Suzuki and Lignos (2015) and Elkady and Lignos (2018)a] (a) Monotonic and firstcycle envelope curves; (b) idealized monotonic backbone and first-cycle envelop curves; (c) Comparisons of measured and simulated column end moment versus chord rotation under symmetric loading history; (d) Comparisons of measured and simulated column end moment versus chord rotation under collapse-consistent loading history 

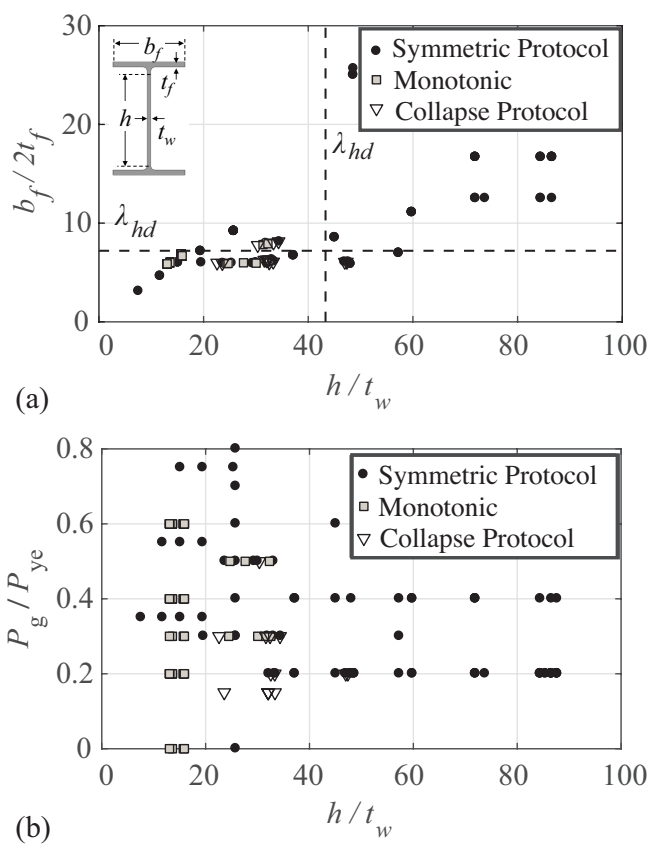

Fig. 2. Cross-section slenderness and axial load ratio ranges of the collected test data (compressive axial load ratio, $P_{g} / P_{y e}$, is indicated with a positive sign) 


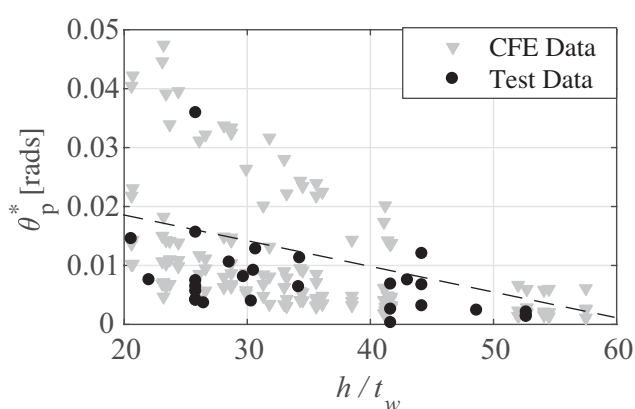

(a)

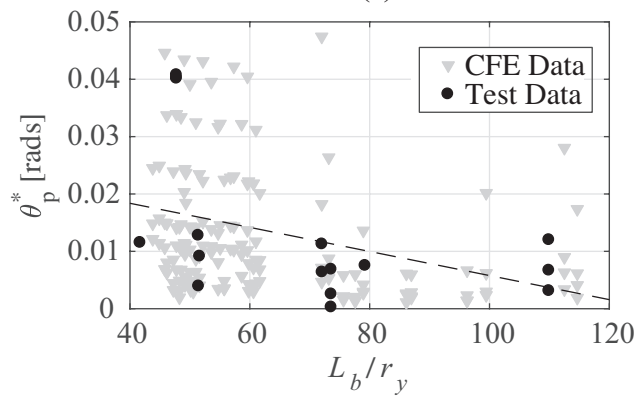

(c)

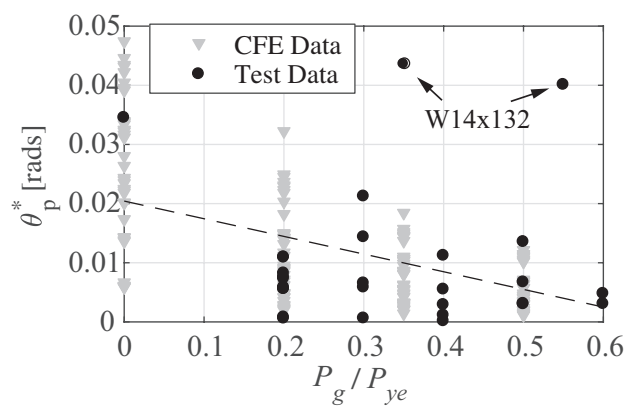

(b)

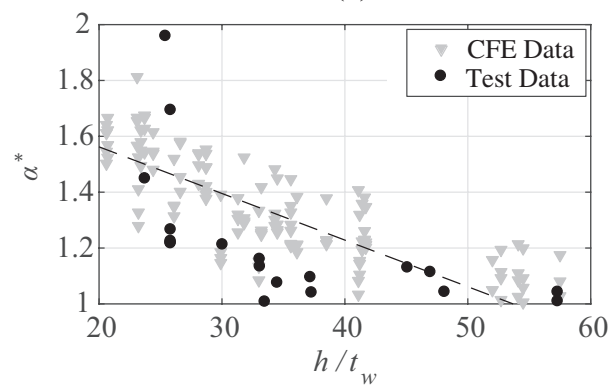

(d)

Fig. 3. Component model parameter trends based on symmetric cyclic loading histories 


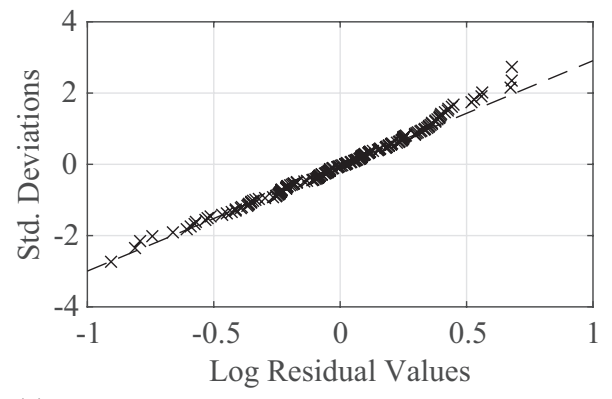

(a)

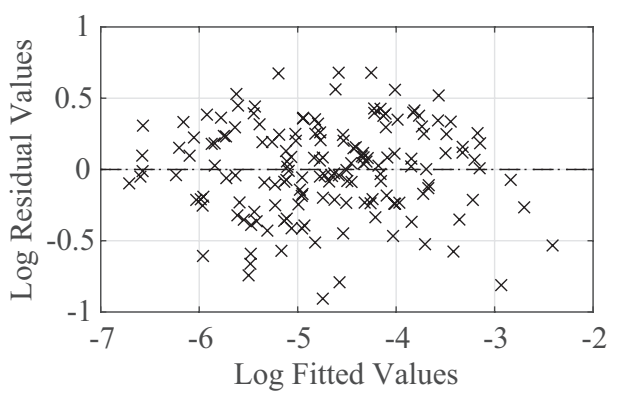

(b)

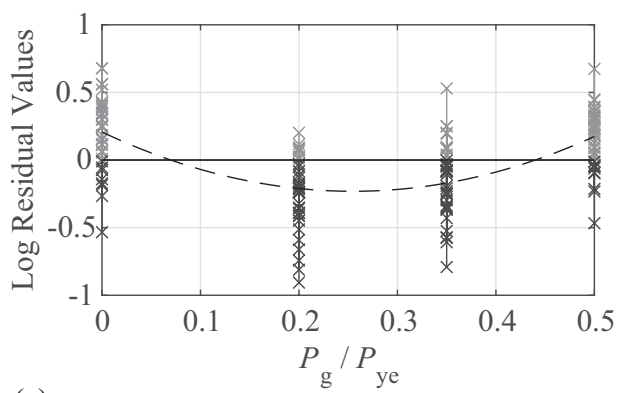

(c)

Fig. 4. Residual values from the regression analysis of pre-peak plastic rotation, $\theta_{p}{ }^{*}$ 


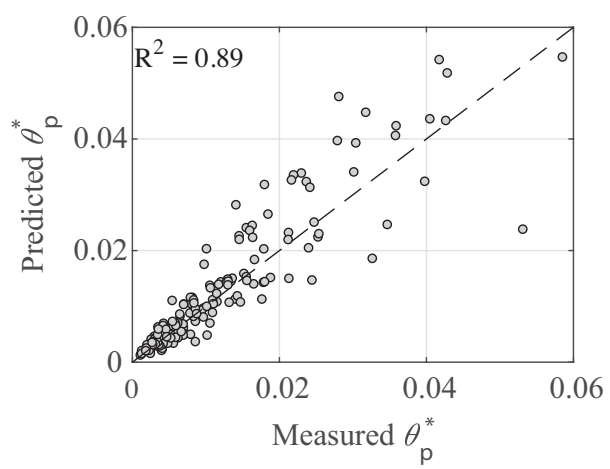

(a)

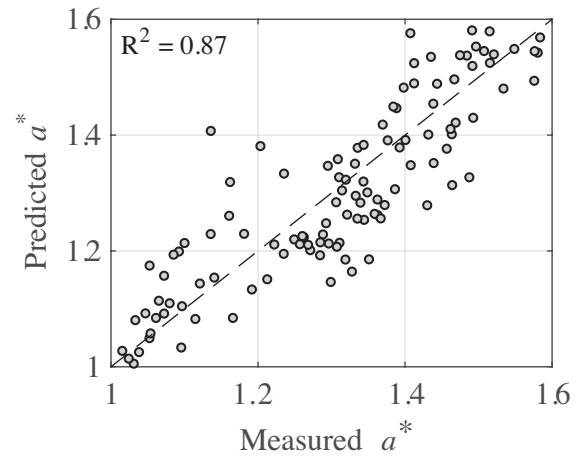

(c)

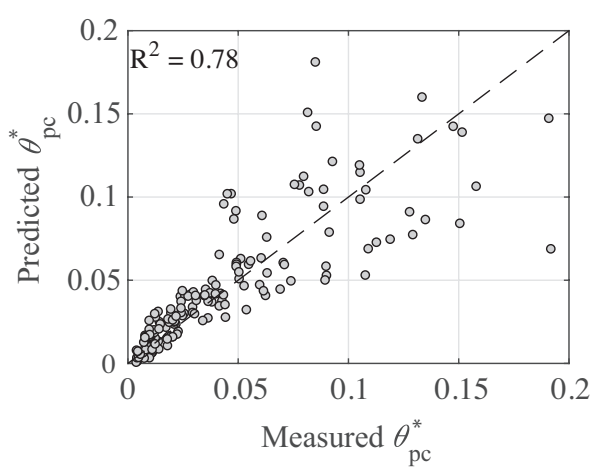

(b)

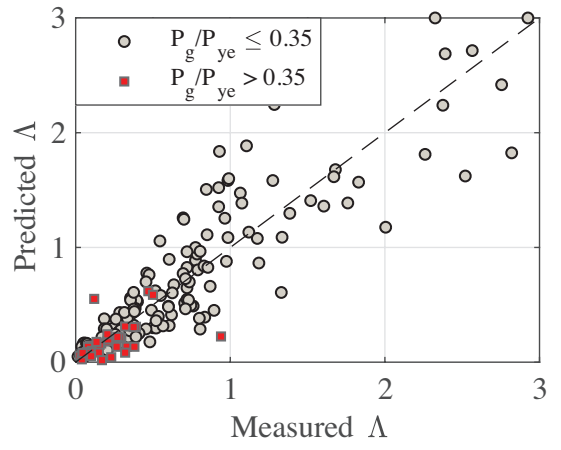

(d)

Fig. 5. Comparison of measured and predicted responses for selected component model parameters 


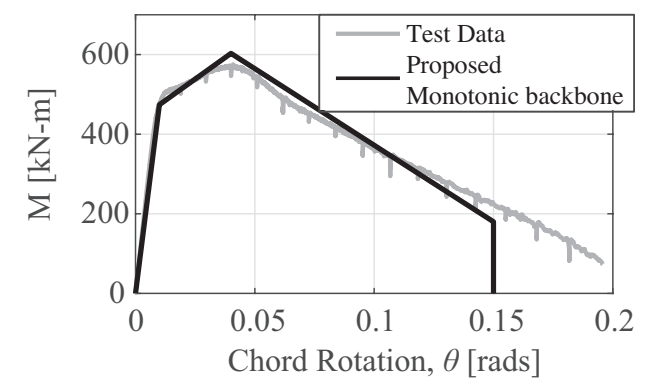

(a) $\mathrm{W} 14 x 53, P_{\mathrm{g}} / P_{\text {ye }}=0.30$

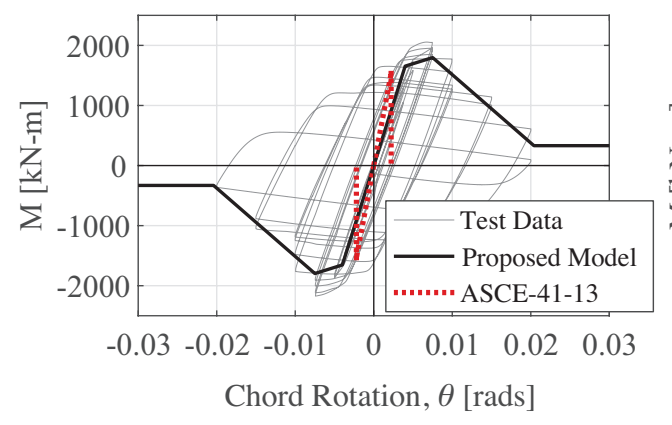

(c) W24x146, $P_{\mathrm{g}} / P_{\text {ye }}=0.50$

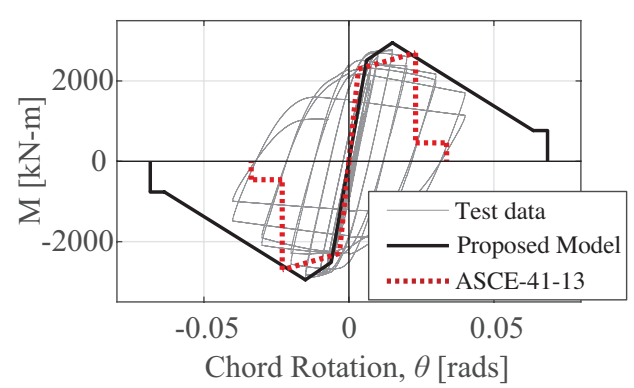

(b) W24x146, $P_{\mathrm{g}} / P_{\mathrm{ye}}=0.20$

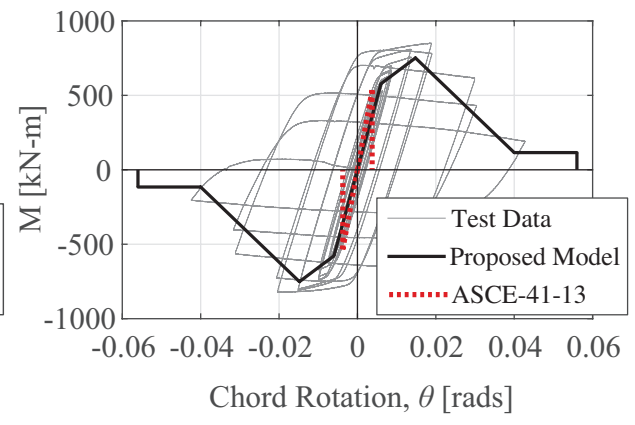

(d) W14x82, $P_{\mathrm{g}} / P_{\text {ye }}=0.30$

Fig. 6. Comparisons between test data, proposed component models, and ASCE 41-13 component modeling recommendations for steel wide flange columns [data from Suzuki and Lignos (2015) and Elkady and Lignos (2018)] 


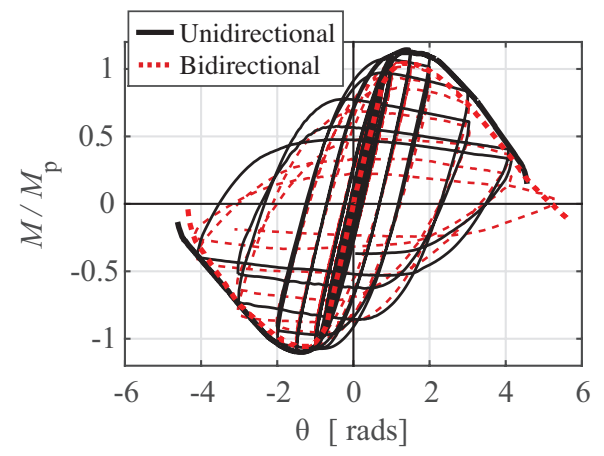

Fig. 7. Wide-flange steel columns (W24x84) subjected to unidirectional and bidirectional lateral loading [data from Elkady and Lignos (2018)] 

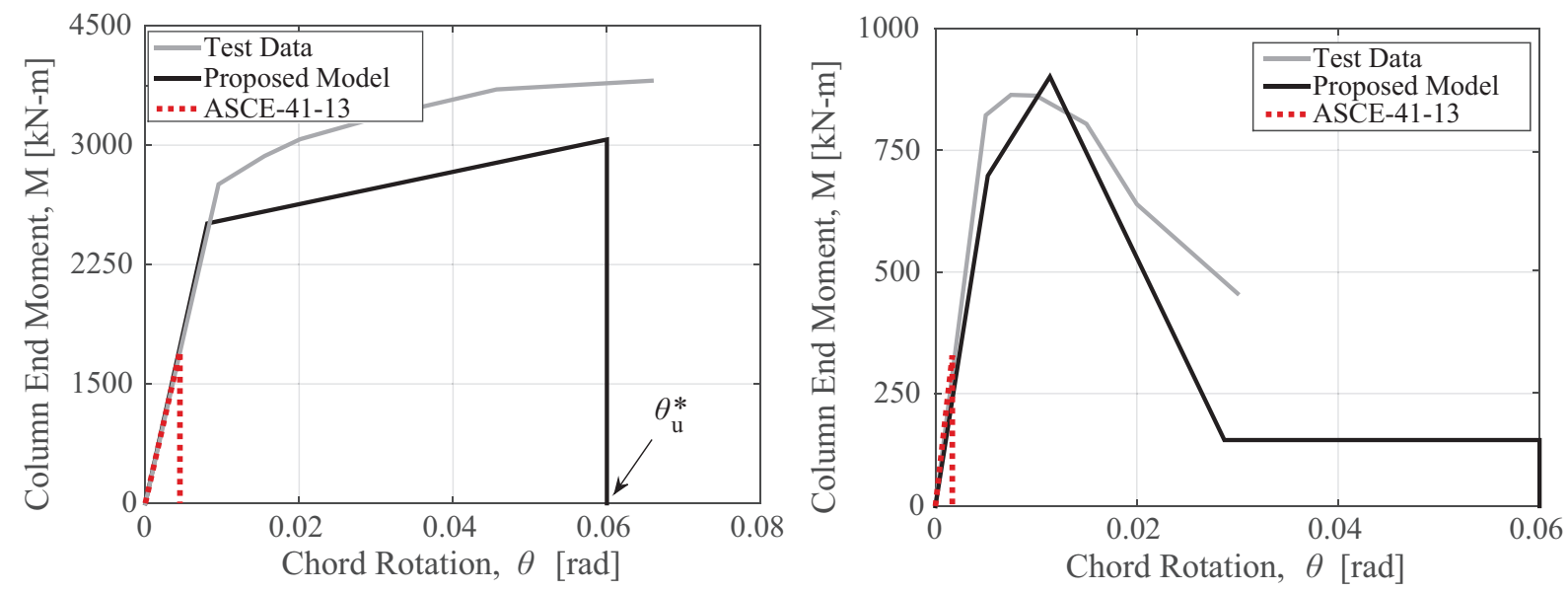

(a) $\mathrm{W} 14 \times 233-55, P_{g} / P_{y e}=0.15, P / P_{y e} \sim-0.15-0.75$ (b) $\mathrm{W} 16 \times 89, P_{g} / P_{y e}=0.50, P / P_{y e} \sim 0.25-0.75$

Fig 8. Comparisons of proposed modeling recommendations with ASCE 41-13 for end columns in steel MRF systems [data from Lignos et al. (2016); Newell and Uang (2008)]. 


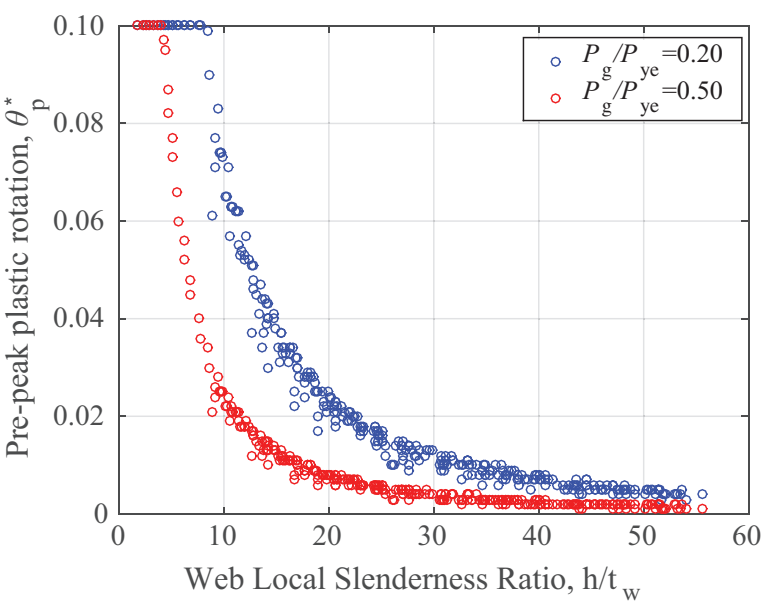

(a)

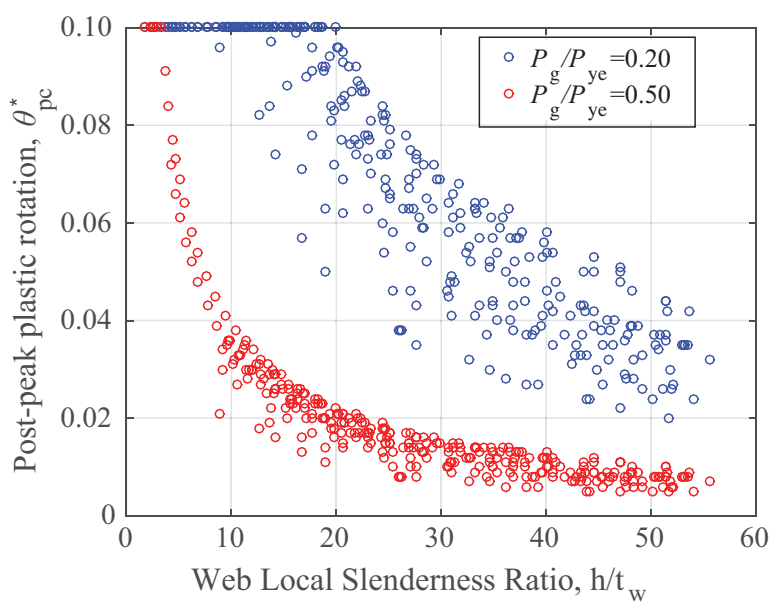

(b)

Fig. 9. Trends of pre- and post-peak plastic rotations with respect to the cross-section web local slenderness ratio for modeling the first-cycle envelope curve of steel wide-flange columns 